RAD Conference Proceedings, vol. 3, pp. 115-118, 2018

ISSN 2466-4626 (online) | DOI: 10.21175/RadProc.2018.25

www.rad-proceedings.org

\title{
ALPHA SELF-ABSORPTION EVALUATION IN RADIOMETRIC FILTER MATERIAL FOR THE NATURAL RANGE OF ALPHA ENERGY (5-9 MeV)
}

\author{
M. Y.A. Mostafa ${ }^{1,3}{ }^{*}$, M.V. Zhukovsky,2 \\ ${ }^{1}$ Department of Experimental Physics, Institute of Physics and Technology, Ural Federal University, Yekaterinburg, \\ Russia \\ ${ }^{2}$ Institute of Industrial Ecology UB RAS, Yekaterinburg, Russia \\ 3Physics Department, Faculty of Science, Minia University, Minia, Egypt
}

\begin{abstract}
In this paper, SRIM (The Stopping and Range of Ions in Matter) software package is used to simulate the interaction of alpha particles into the material of radiometric analytical filters. The effect of alpha particle selfabsorption in alpha radiometric filters measurements is estimated, especially in the range of natural alpha energy (5$9 \mathrm{MeV}$, Radon and Thoron alpha energy). Software package SRIM allows to calculate the parameters of the ions interaction with target material using a Monte Carlo simulation method based on a quantum mechanical treatment of ion-atom collisions. The effect of the radiometric analytical filter material on the transmitted efficiency of alpha energy is discussed. As the energy increases the self-absorption in analytical filter material is decreased but still has a clear effect. In this case, the filter material and the space distance between the filter and the detector window decrease the number of alpha particles which reach to the detector window.
\end{abstract}

Key words: SRIM, radiometric filters, alpha particles penetration

\section{INTRODUCTION}

It is known that alpha particles can be absorbed by a thin sheet of paper or by a few centimeters of air. As alpha particles travel through the air they collide with nitrogen and oxygen molecules. With each collision they lose some of their energy in ionizing the air molecule until eventually they give up all of their energy and are absorbed. In a sheet of paper, the molecules are much close together (denser) so the penetration range of alpha particles is much less than in the air. The penetration of alpha particles is strongly depending on the density of matter. In the case of radiometric analytical filter, the surface density of the filter $\left(\mathrm{mg} \mathrm{cm}^{-2}\right)$ can vary according to filter material type. The surface density affects the penetration range of alpha particles. Therefore, we can state that, compared to other types of radiation, alpha particles have a very high rate of energy loss in matter thus making it heavily ionizing radiation. Consequently, the penetration depth of alpha particles is very small in different materials compared to the other types of radiations $(\beta, \gamma \ldots$ etc.).

Air sampling for radioactive aerosols involves sampling of airborne particles with an analytical filter in order to measure radioactivity in the environment. The amount of alpha radioactivity collected on the analytical filter sampling is frequently estimated by global alpha-particles measurements. There are many factors that can affect alpha energy while passing through the filter to reach the detector. The most important factor which has a great effect on the alpha measurement is the absorption of alpha particle energies in the filter material in addition to the air distance between the filter and detector window. The counting losses can accordingly be important, and the global activity in the filter can be under estimated.

The detection efficiency of the alpha particles has been previously investigated in many articles; for example, in Ref. [1] and the references therein. Alphaparticle energy loss has also been studied, e.g. [2-6].

For the environmental radioactivity survey, the part of alpha particles absorbed inside the filter is generally not considered in the activity calculations. The reason is that the experimental method commonly used to determine the correction factors is very complicated and time-consuming [7].

All alpha particles from a given nuclear transition emerge with the same kinetic energy and have a range $\mathrm{R}$ (in $\mathrm{mg} \mathrm{cm}^{2}$ ) through a material. An alpha particle with a range $\mathrm{R}$ passes through a thickness less than $\mathrm{R}$, emerging nearly undeflected, but with less than its original energy. All alpha particles emitted in a filter pass through a part or the entire front layer and then through the air space and the detector window. If the total thickness of these three materials is less than R, all alpha particles are counted if the detector is $100 \%$ efficient; if not, as usual, there is a loss in the counted alpha particles that should be considered.

\footnotetext{
*mostafa85@mail.ru
} 
M.Y.A. Mostafa and M.V. Zhukovsky, Alpha self-absorption evaluation..., RAD Conf. Proc., vol. 3, 2018, 115-118

The fiber filters are often used in the environmental air sampling to collect particulate matter from the air. The reason is that filters ensure low pressure and high filtration. The amount of alpha radioactivity inside the filter is measured with alpha detectors. The particulate matter becomes imbedded throughout the front surface of the filter, so the front layer consists of both filter and particulate matter. Alpha particles originating in the filter pass through a part or all of the front layer of the filter to reach the detector. These alpha particles must pass through the air between the filter and the detector and through the window of the detector. Therefore, most alpha particles lose significant energy while passing through the filter; some alphas lose all their energy. When an alpha is measured with semi-conductor detectors, count spreading inevitably takes place, even without significant dust loading on the filter. The fraction of alpha counts lost due to the aerosol burying has been previously investigated by many authors. Higby determined this loss as the ratio of activity detected by direct alpha counts to the activity determined by photon spectrometry [8]. This study suggests the absorption between $\mathrm{O}$ and $25 \%$ of alpha counts. A correction factor between 10 and $15 \%$ for alpha counts is recommended. Recently, Luetzelschwab et al. showed that counting losses is important [9]. For 4 $\mathrm{MeV}$ and $7.5 \mathrm{MeV}$ alpha particles, the absorption in glass fiber filter is $43 \%$ and $13 \%$ respectively [9]. Geryes et al. gave a $25 \%$ lower alpha correction for selfabsorption than that reported by Luetzelschwab et al. due to differences in the detection technique between the two studies [1]. However, the results are close to that reported by Higby [8] in their study on the selfabsorption of alpha in glass fiber filters.

Based on the use of AFA-filters for EEC calibration measurement system in previous work [10], the aim of this study is to present a Monte Carlo simulation, to evaluate the penetration/transmission efficiency of the alpha particles through radiometric analytical filter AFA-RSP-20 $\left(3.5 \pm 0.5 \mathrm{mg} / \mathrm{cm}^{2}\right)$ which is widely used in alpha radiometric measurements [10]. In this research, the SRIM software package (The Stopping and Range of Ions in Matter) is used [4]. A special input file is created for this purpose. Finally, the effect of the analytical filter material on the registered alpha particles to the detector is estimated at different distributions of alpha energy inside the filter.

\section{MATERIALS AND METHODS}

The alpha radioactivity measurement depends on the detector characteristics, geometry setup of the experiment, filter characteristic, and filtration conditions. Figure 1 shows the experimental set up of alpha radiometry with an alpha scintillation detector and analytical radiometric filter. On the left side, the shape of analytical filter AFA-RSP-20 is presented. In the real experiment after radioactive aerosols filtration through the filter, the filter is placed in the front of scintillation detector to measure the alpha activity (real experiment used in many times [10]). The distance between the end of filter and the surface detection area of detector is $\sim 3 \mathrm{~mm}$. The thickness of the filter is 0.3 $\mathrm{mm}$ and the density is $0.12 \mathrm{gm} / \mathrm{cm}^{3}$ of a composite fibrous polymeric material containing Nano fiber layers of Polyvinyl carbonate (PVC).

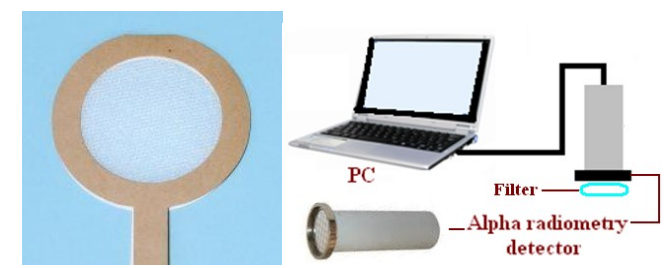

Figure 1. Experimental setup of AFA-RSP analytical filter with Alpha radiometry.
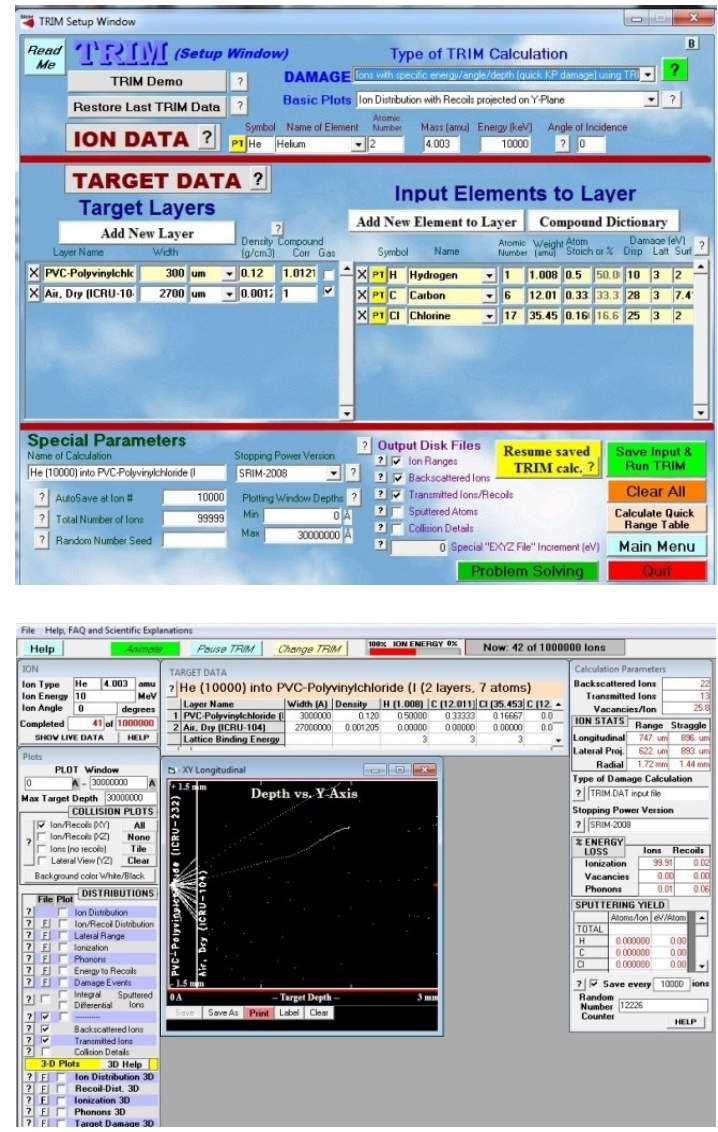

Figure 2. Input data for simulation of alpha detection according to alpha radiometry measurement.

In Figure 2, the initial data of real experiment with the radiometric analytical filter is inserted to the SRIM software package. The type of filter material is PVC Polyvinyl carbonate with thickness $0.3 \mathrm{~mm}$ at $2.7 \mathrm{~mm}$ of dry air from the detection area of the scintillation detector (detector window), as shown in the upper window. In the lower window of Figure 2 the starting simulation is running with $10 \mathrm{k}$ of alpha particles with fixed alpha energy. The alpha energy is supposed to be distributed inside the filter material.

In this simulation, three different distributions of alpha particles inside the filter from the upper layer of filter surface area till the end of the filter are assumed 
M.Y.A. Mostafa and M.V. Zhukovsky, Alpha self-absorption evaluation..., RAD Conf. Proc., vol. 3, 2018, 115-118

as (50:30:20) \%, (60:20:10) \% and (70:20:10) \%. The input files for this case are created for different alpha energies. The simulation was performed for each energy.

\section{RESULTS AND DISCUSSION}

The simulation windows of the $10 \mathrm{k}$ of alpha particles (energy $7.78 \mathrm{Mev}$ as example) in $2.7 \mathrm{~mm}$ dry air and in $0.3 \mathrm{~mm}$ radiometric analytical filter material of AFA-RSP-20 (PVC) added to $2.7 \mathrm{~mm}$ dry air using the software package SRIM is presented in Figure 3 . The difference between the transmutations in these two cases is clear. Unlike in the dry air case when the filter layer is added, a lot of alpha particles are stopped in the filter material layer and some are stopped in the air distance before reaching the detector. In the upper case, alpha particles only pass through air. In the lower case, the filter is added and apart of alpha particles completely stopped. Another part of alpha particles loss parts of their energy to pass the filters then also stopped in the space distance before reaching to the detector window.
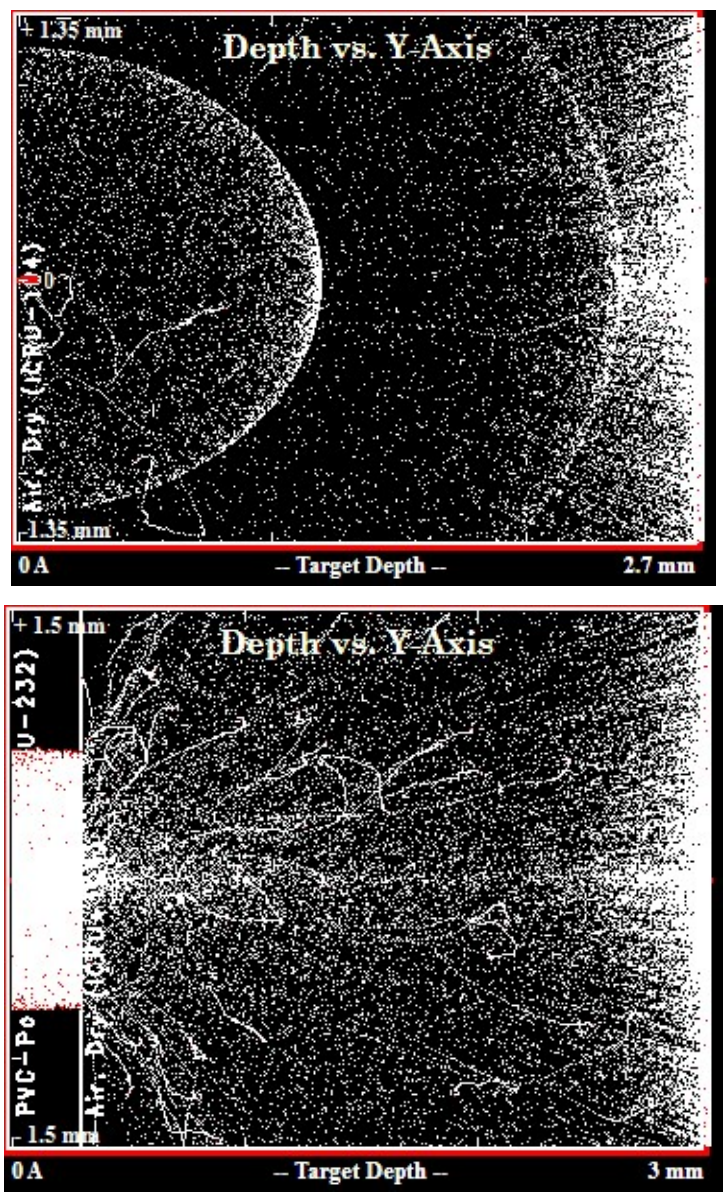

Figure 3. Simulation of the 104 Alpha particles (energy 7.78) $\mathrm{Mev}$ in $2.7 \mathrm{~mm}$ dry air and in 0.3 radiometric filter material of AFA-RSP-2O (PVC) add to $2.7 \mathrm{~mm}$ dry air using software package SRIM.
Figure 4 presents the ion distribution of the alpha particle (energy $=7.78 \mathrm{MeV}$ ) in the material of radiometric filter AFA-RSP-20 (PVC) and in the dry air between the filter and alpha detector. Compared to dry air, the PVC thickness $(0.3 \mathrm{~mm})$ is the ionized region for penetrating alpha energy particles. This indicates the great effect of filter layer relative to space distance to the detector during the density effect.

The transmitted efficiencies (ratio of particles that reached to the detector window) of $10 \mathrm{k}$ alpha particles with energy of known radioactive sources from 5 to $9 \mathrm{MeV}$ ( ${ }^{239} \mathrm{Pu},{ }^{210} \mathrm{Po},{ }^{241} \mathrm{Am},{ }^{218} \mathrm{Po},{ }^{216} \mathrm{Po},{ }^{214} \mathrm{Po}$ and $\left.{ }^{212} \mathrm{Po}\right)$ are simulated and calculated for $2.7 \mathrm{~mm}$ dry air and for $0.3+2.7 \mathrm{~mm}$ (PVC + dry air). For dry air, the transmitted efficiency is nearly constant at different alpha energy $\sim 45 \%$. This result is due to the distance of $2.7 \mathrm{~mm}$, which is at least ten times less than the range of these alpha energies in air, see Table 1.

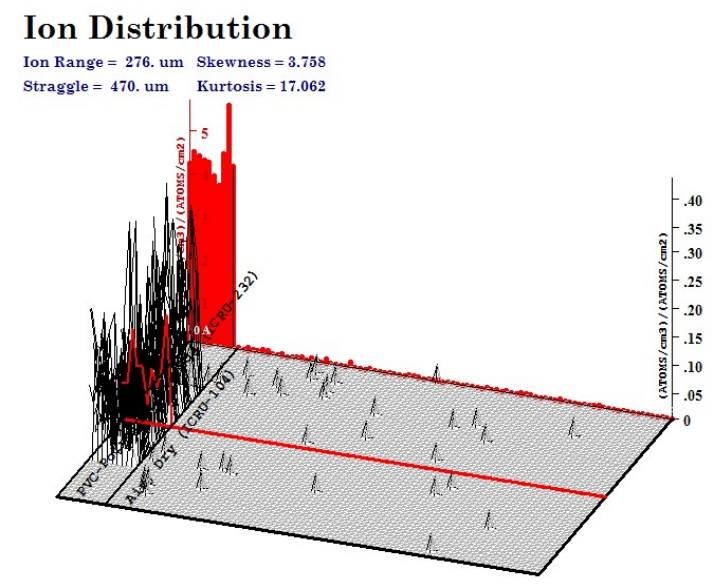

Figure 4. Ion distribution of the alpha particle in the material of radiometric filter AFA-RSP-20 (PVC) and in the dry air space tell alpha radiometry detector at energy $7.78 \mathrm{MeV}$.

Table 1. Range of different alpha energy in dry air.

\begin{tabular}{c|c|c}
\hline $\begin{array}{c}\text { Alpha } \\
\text { emitter }\end{array}$ & $\begin{array}{c}\text { Energy } \\
\text { MeV }\end{array}$ & $\begin{array}{c}\text { Range in Dry air } \\
\text { cm}^{*}\end{array}$ \\
\hline Pu-239 & $5.16 \mathrm{E}+00$ & 3.79 \\
Po-210 & $5.30 \mathrm{E}+00$ & 3.95 \\
$\mathrm{Am}-241$ & $5.49 \mathrm{E}+00$ & 4.19 \\
Po-218 & $6.00 \mathrm{E}+00$ & 4.82 \\
Po-216 & $6.78 \mathrm{E}+00$ & 5.79 \\
Po-214 & $7.68 \mathrm{E}+00$ & 6.90 \\
Po-212 & $8.78 \mathrm{E}+00$ & 8.27 \\
\hline \multicolumn{2}{|c}{${ }^{*} \mathrm{R}=1.24 \mathrm{E}+2.62$ for $4 \leq \mathrm{E} \leq 8 \mathrm{MeV}$}
\end{tabular}

The transmitted efficiency of the Alpha particles in the dry air and in the material of radiometric filter AFA-RSP-20 (PVC) as a function of alpha energy for 10 $\mathrm{k}$ alpha particles using a software package SRIM is shown in Figure 5. For a different distribution of alpha particles inside the filter material, there is no significant change in the penetration efficiency. In general, penetration efficiency increased with the 
M.Y.A. Mostafa and M.V. Zhukovsky, Alpha self-absorption evaluation..., RAD Conf. Proc., vol. 3, 2018, 115-118

increasing of alpha energy as expected. For Po-212 $(8.78 \mathrm{MeV})$ the loss of penetration efficiency is due to filter material nearly $5 \%$. At low energy this loss presents increases till $20 \%$ for Pu-239 (5.16 MeV). For radon decay products (Po-218 and Po-214) the loss is $15 \%$ and $10 \%$ respectively. These values cannot be neglected and should be considered in the measurements of radon and thoron decay products with analytical filters.

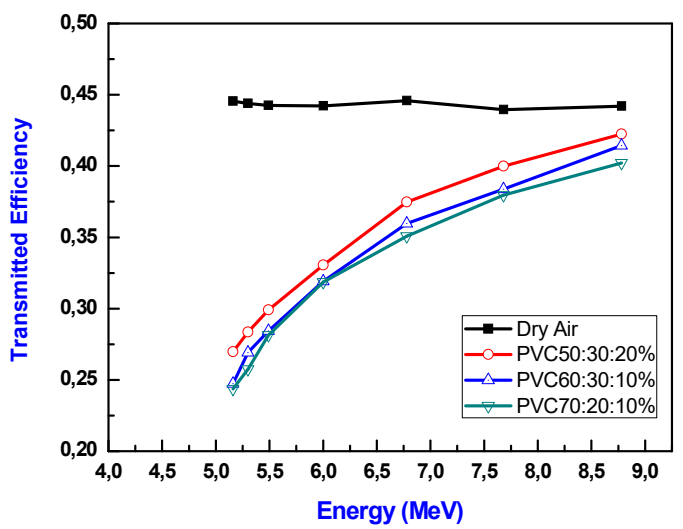

Figure 5. Efficiency of the transmitted alpha particles in the dry air and in the material of radiometric filter AFA-RSP-20 (PVC) as a function of alpha energy for 104 Alpha particles using software package SRIM.

\section{CONCLUSIONS}

1. The penetration of alpha energies particles in a radiometric analytical filter is simulated. This is simulation of real measurements of alpha activities with radiometric analytical filters

2. The transmitted efficiencies of alpha particles with energy of known radioactive sources from 5 to $9 \mathrm{MeV}\left({ }^{239} \mathrm{Pu},{ }^{210} \mathrm{Po},{ }^{241} \mathrm{Am},{ }^{218} \mathrm{Po}\right.$, ${ }^{216} \mathrm{Po},{ }^{214} \mathrm{Po}$ and ${ }^{212} \mathrm{Po}$ ) are simulated and the effect is presented.

3. At energy of Pu-239 (5.16 MeV) the loss inside filter materials nearly $20 \%$ and decrease to $5 \%$ For Po-212 (8.78 MeV).

4. For radon (Po-218 and Po-214) the energy loss in the filter material is $15 \%$ and $10 \%$ respectively.

5. This correction must be considered for accurate radioactivity estimation in filters.

\section{REFERENCES}

1. R. Whitcher, "Calculation of the average solid angle subtended by a detector to source in a parallel plane by a Monte Carlo method," Radiat. Prot. Dosim., vol. 102, no. 4, pp. $365-369,2002$.

DOI: 10.1093/oxfordjournals.rpd.a006107 PMid: 12474948

2. S. Pickering, "The interpretation of alpha energy spectra from particulate sources," J. Aerosol Sci., vol. 15, no. 5, pp. $533-543,1984$. DOI: $10.1016 / 0021-8502(84) 90016-8$

3. R. J. Krupa, K. Kurzak, "Simulation and evaluation of aspectra obtained with semiconductor detectors," Nucl. Instrum. Methods A, vol. 307, no. 2-3, pp. $469-483$, Oct. 1991.

DOI: 10.1016/0168-9002(91)90220-K

4. C. Roldán, J. L. Ferrero, F. Sanchez, E. Navarro, M. J. Rodriguez, "Monte Carlo simulation of alpha spectra in low geometry measurements," Nucl. Instrum. Methods A, vol. 338, no. 2-3, pp. 506 - 510, Jan. 1994. DOI: 10.1016/0168-9002(94)91334-X

5. F. A. Seiler, G. J. Newton, R. A. Guilmette, "Continuous monitoring for airborne alpha emitters in a dusty environment," Health Phys., vol. 54, no. 5, pp. 503 - 515, May 1988.

DOI: 10.1097/00004032-198805000-00002 PMid: 2834306

6. T. Geryes, C. Monsanglant-Louvet, E. Gehin, "Experimental and simulation methods to evaluate the alpha self-absorption factors for radioactive aerosol fiber filters," Radiat. Meas., vol. 44, no. 9-10, pp. $763-765$, Oct-Nov. 2009.

DOI: 10.1016/j.radmeas.2009.10.059

7. D. P. Higby, Effects of Particle Size and Velocity on Burial Depth of Airborne Particles in Fiber Filters, Rep. PNL-5278, National Technical Information Service., Springfield (VA), USA, 1984.

Retrieved from: https://www.osti.gov/servlets/purl/63 $\underline{12811}$

Retrieved on: Jun. 25, 2018

8. J. W. Luetzelschwab, Ch. Storey, K. Zraly, D. Dussinger, "Self-absorption of alpha and beta particles in a fiberglass filter," Health Phys., vol. 79, no. 4, pp. 425 - 430, Oct. 2000.

DOI: 10.1097/00004032-200010000-00012 PMid: 11007466

9. J. F. Ziegler, M. D. Ziegler, J. P. Biersack, "SRIM The Stopping and Range of Ions in Matter," Nucl. Instrum. Methods Phys. Res. B, vol. 268, no. 11-12, pp. $1818-1823$, Jun. 2010. DOI: 10.1016/j.nimb.2010.02.091

10. Y. A. M. Mostafa, M. Vasyanovich, M. Zhukovsky, N. Zaitceva, "Calibration system for radon EEC measurements," Radiat. Prot. Dosimetry, vol. 164, no. 4, pp. $587-590$, Jun. 2015.

DOI: $10.1093 / \mathrm{rpd} / \mathrm{ncv} 316$

PMid: 25979737 